\title{
Management of floating knee
}

\author{
Anil Kumar Joshi • Saurabh Singh • Vivek Trikha
}

Received: 15 January 2007 /Revised: 19 January 2007 / Accepted: 21 January 2007 / Published online: 3 February 2007

(C) Springer-Verlag 2007

\section{Dear Editor,}

We have read with great pleasure the article entitled "Ipsilateral fractures of tibia and femur or floating knee" [1]. We would like to congratulate the authors for evaluating the issue very well. They have definitely made a great contribution to the relevant literature on intramedullary (IM) nailing. IM nailing has become the gold standard to stabilise these fractures in immediate or delayed settings [2].

We would like to say that it is an era of "limb damage control orthopaedics," which must be considered when dealing with polytrauma patients. During the 1990s it was advocated that the adverse outcome of fracture surgery, especially IM nailing, had systemic physiological effects known as "second-hit phenomena." A major concern being to decrease second-hit phenomena, a more selective approach to fracture fixation was used; however, early

\footnotetext{
A. K. Joshi $\cdot$ S. Singh $\cdot$ V. Trikha $(\triangle)$

Department of Orthopaedics,

All India Institute of Medical Sciences,

New Delhi, India

e-mail: vivektrikha@rediffmail.com
}

fixation was still performed in most cases. This phenomenon, which particularly increases with reamed IM nailing in polytrauma patients, results in increased chances of pulmonary complications $[3,4]$.

We would like to draw the authors' attention to the fact that they have not mentioned the approach for IM nailing. We suggest use of a single longitudinal incision over the knee for retrograde nailing of femur and antegrade nailing tibia in a single session with the advantage of decreasing the operative time and morbidity while obtaining equally good results [5].

\section{References}

1. Elmrini A, Elibrahimi A, Agoumi O et al (2006) Ipsilateral fractures of tibia and femur or floating knee. Int Orthop 30:325328 DOI 10.1007/s00264-006-0084-0

2. Craig SR, Pape HC et al (2005) J Bone Jt Surg Am 87:434-449

3. Giannoudis PV, Smith RM et al (1999) Stimulation of the inflammatory system by reamed and unreamed nailing of femoral fractures. An analysis of the second hit. J Bone Jt Surg Br 81:359

4. Ribet ME (1994) "Damage control" in trauma surgery. Br J Surg $81: 627$

5. Robert WB, James DH (1994) Fractures in adults.Vol. 3, 5th edn. 41:1705-1706 